\title{
Muscular ventricular septal defects: how I close them
}

\author{
Vinod A. Sebastian \\ Department of Pediatric Cardiac Surgery, Rocky Mountain Hospital for Children, Denver, CO, USA \\ Correspondence to: Vinod Sebastian. Department of Pediatric Cardiac Surgery, Rocky Mountain Hospital for Children, Denver, CO, USA. \\ Email: vinodas@yahoo.com.
}

Submitted Sep 29, 2019. Accepted for publication Dec 02, 2019.

doi: $10.21037 /$ jtd.2019.12.29

View this article at: http://dx.doi.org/10.21037/jtd.2019.12.29

A ventricular septal defect (VSD) is a communication between the interventricular chambers. Muscular ventricular septal defects have exclusively muscular borders and are more likely to be multiple. Their location and multiplicity can sometimes make them a very challenging clinical problem.

\section{Types of VSDs}

The different types of VSDs include perimembranous VSD, conoventricular VSD, supracristal VSD, muscular VSD and inlet atrioventricular canal type VSD.

Muscular VSDs can be further classified as

(I) Midmuscular VSD;

(II) Inlet muscular VSD;

(III) Apical muscular VSD;

(IV) Anterior trabecular VSD;

(V) Multiple VSDs or "Swiss-cheese" VSD.

\section{Clinical presentation}

Most patients with muscular VSDs are asymptomatic and majority will not require surgical or any other intervention to close them. Patients that have small muscular VSDs will often develop ventricular hypertrophy and have no significant shunt with somatic growth. If the defect is large or; in cases of multiple VSDs if the combined shunt is high, patients may become symptomatic in early infancy.

The management of a single muscular VSD in the inlet area is very similar to the management of a perimembranous VSD. Medical management can be used till the age of 3 months to control symptoms and then surgical closure of the VSD can be done. My preference of patch material is autologous pericardium sutured in with a continuous prolene suture, though other techniques like interrupted sutures or other patch material can also be used. Care must be paid to the location of the conduction system because in these patients, the atrioventricular conduction axis penetrates into the ventricular septum on the superior side of the VSD and extreme care must be taken while placing sutures on the superior edge of the VSD.

In patients that have both perimembranous and an inlet muscular VSD I prefer to use a single patch to close both defects. This avoids taking sutures in the narrow muscle bundle between these two defects. Most likely in this subgroup the bundle of His travels in this narrow muscle bundle.

Isolated mid muscular VSDs are most accessible to closure in the catheterization lab. Most of these patients will never see a cardiac surgeon, though hybrid approaches have been advocated by some surgeons and cardiologists.

I consider mid muscular VSDs, apical muscular VSDs and anterior trabecular VSDs as a "field of defects". Several times, these VSDs may have one or two openings on the compact left ventricular side but have several openings on the trabeculated non compact right ventricular (RV) side. Closure of this "field of defects" cannot be done with the typical technique used in the closure of perimembranous VSDs. In a perimembranous VSD, the margins of the VSD are easily defined and should be covered with an exact sized patch and fine needles that only go through the exact margin of the VSD. In muscular VSDs, I always get an approximate idea of where the "field of defects" is from the echocardiogram. Intraoperatively I approach them through the right atrium and then use an oversized patch that goes a bit beyond this "field of defects". In infants, I use a 5.0 


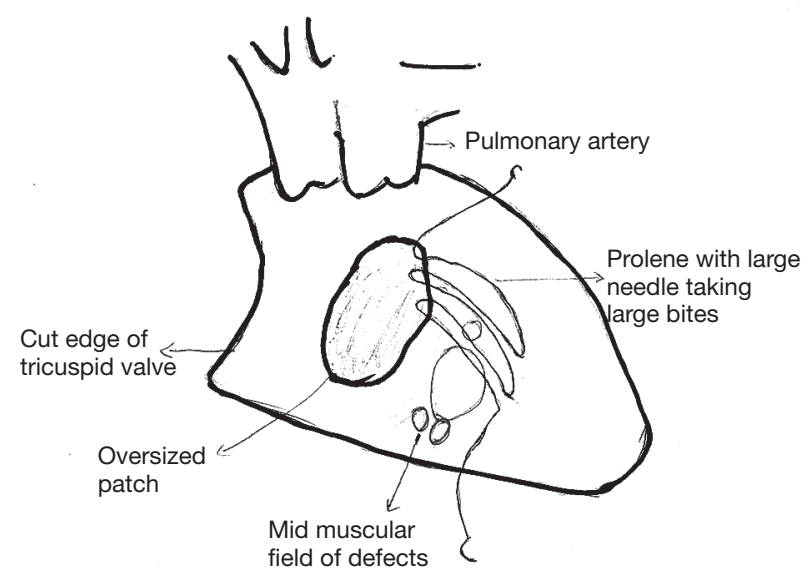

Figure 1 Figure shows a large patch being used to close the zone of defects in mid muscular VSDs. VSD, ventricular septal defect.

prolene suture with a bigger needle which would otherwise rarely be used on neonatal or infant VSDs (Figure 1). The larger needle allows me to compensate for any additional extensions of the "field of defects" that I might encounter while sewing in the patch. Any suspicious trabeculations at the periphery of the field will be included.

In the case of mid muscular VSDs, the moderator band may be at the bottom of the defect or may traverse the defect. Some surgeons describe dividing the moderator band completely to visualize the defect. This is not my preference. Since I am only looking for the approximate "field of defect" most of the times I can use an oversized patch to exclude that field from the remaining RV cavity. Minor muscle bundles may be divided to position the patch under or over the moderator band.

Other techniques may be used for closure like a hybrid approach with a perventricular device closure or by placing the patch on the left ventricular side either through the VSD or via a separate left ventriculotomy. The long-term consequences of a left ventriculotomy are always a concern with this approach. When the patch is placed via the VSD onto the left ventricular side, then the left ventricular pressure helps in fixing the patch since it is higher than RV pressure (2).

Apical VSDs have all the characteristics described above for mid muscular VSDs. However, their location further distally near the ventricular apex can make exposure more difficult. In these apical VSDs, I have not used the typical short length retractors, like a vein retractor, often used in perimembranous VSDs. I have found that a Teflon coated narrow malleable bent to the appropriate shape can provide excellent exposure deeper into the RV cavity. Teflon coated retractors have better traction on the RV muscle and do not slip as easily as a metal malleable retractor would, when used in this circumstance. Once this exposure is obtained, then I again identify the field of defects in the apex. Once this is done, then I use another oversized patch to close these defects. Rather than trying to define the exact margin of each individual defect, a more effective strategy is to attempt to exclude this field of defects from the main RV chamber. Dimpling of the epicardium can often be seen with this because the larger needle allows me to take bigger bites of the trabeculations at the margin of this field of defects. Care must be taken not to get close to the left anterior descending (LAD). If this happens, epicardial scoring incisions can be made to ensure the LAD lumen isn't compromised. If at the completion of the procedure the apical VSD patch is felt to be too patulous and impinging on the RV cavity, then a few anchor sutures with pledgets may be passed through the patch and brought out through the ventricular apical epicardium. Normal cardiovascular surgical needles do not have the length for this maneuver so I have used straight 23 -gauge hollow bore hypodermic needles to pass these anchoring sutures. Closure of anterior apical VSDs can be the most challenging because of the proximity to the LAD so extra caution must be taken.

Anterior VSDs away from the apex can be closed by suturing the patch to the annulus of the pulmonary valve and using the remainder of the patch to exclude this field of defects from the RV chamber. This patch should also be generous but should not be oversized that it billows into the RV outflow tract.

An additional maneuver that is helpful in case of multiple VSDs, is by passing a right-angled clamp through the VSD closest to the inlet to define the field of defects distally.

At the end of the procedure, saline may be insufflated through the atrial septal defect (ASD) and mitral valve to check if the ventricular septum can be made to bulge into the right ventricle. If this happens then its highly likely that most of the interventricular shunt has been closed. Also, if the left ventricle $(\mathrm{LV})$ vent is draining mostly blood and not a mixture of air and blood, this could be an indirect sign of complete closure.

Muscular VSDs may also be associated with coarctation or transposition. In case of transposition, a useful technique is to introduce a right angle through the neoaortic valve and probe the VSDs. Since the right angle is on the LV side it is more likely to "fall into" the VSD and a heavy silk suture can be passed from the tricuspid valve. This is a useful marker of the "field of defects" that needs to be closed. 
At the end of the procedure, if there is any residual VSDs seen on the post-operative echocardiogram then I do an estimation of the shunt fraction by drawing superior vena caval blood and pulmonary arterial blood at $30 \% \mathrm{FiO}_{2}$. If the shunt fraction is less than 1.5 then $\mathrm{I}$ consider it a satisfactory result. For higher shunt fractions, I make a judgement call if there are accessible additional VSDs to decide for further attempts at closure versus a pulmonary artery (PA) band. I have personally found a right ventriculotomy of limited use since it allows access only to the anterior part of the interventricular septum.

In conclusion, muscular VSDs are a challenging problem in neonates and infants when they present with significant congestive heart failure from interventricular shunting. However, with careful adjustments to technique, most of these can be closed via the right atrium and rarely need the use of a ventriculotomy or a PA band.

\section{Acknowledgments}

Funding: None.

\section{Footnote}

Provenance and Peer Review: This article was commissioned and reviewed by the Guest Editor (Raghav A. Murthy) for the series "Management of Congenital Heart Disease" published in Fournal of Thoracic Disease. The article did not undergo external peer review.

Cite this article as: Sebastian VA. Muscular ventricular septal defects: how I close them. J Thorac Dis 2020;12(3):1260-1262. doi: $10.21037 /$ jtd.2019.12.29
Conflicts of Interest: The series "Management of Congenital Heart Disease" was commissioned by the editorial office without any funding or sponsorship. The author has no other conflicts of interest to declare.

Ethical Statement: The author is accountable for all aspects of the work in ensuring that questions related to the accuracy or integrity of any part of the work are appropriately investigated and resolved.

Open Access Statement: This is an Open Access article distributed in accordance with the Creative Commons Attribution-NonCommercial-NoDerivs 4.0 International License (CC BY-NC-ND 4.0), which permits the noncommercial replication and distribution of the article with the strict proviso that no changes or edits are made and the original work is properly cited (including links to both the formal publication through the relevant DOI and the license). See: https://creativecommons.org/licenses/by-nc-nd/4.0/.

\section{References}

1. Jacobs ML, Jacobs JP. Operative techniques for repair of muscular ventricular septal defects. Operative Techniques in Thoracic and Cardiovascular Surgery 2010;15:2-17.

2. Kitagawa T, Durham LA 3rd, Mosca RS, et al. Techniques and results in the management of multiple ventricular septal defects. J Thorac Cardiovasc Surg 1998;115:848-56. 